\title{
The incidence, risk factors and predictive nomograms for early death among patients with stage IV gastric cancer: a population-based study
}

\author{
Yi Yang, Zi-Jiao Chen, Su Yan \\ Department of Gastroenterology, The First Affiliated Hospital of Soochow University, Suzhou, China \\ Contributions: (I) Conception and design: Y Yang, ZJ Chen, S Yan; (II) Administrative support: Y Yang, S Yan; (III) Provision of study materials or \\ patients: Y Yang, S Yan; (IV) Collection and assembly of data: Y Yang, JZ Chen; (V) Data analysis and interpretation: Y Yang, S Yan; (VI) Manuscript \\ writing: All authors; (VII) Final approval of manuscript: All authors. \\ Correspondence to: Su Yan, PhD. Department of Gastroenterology, The First Affiliated Hospital of Soochow University, 899 Pinghai Road, Suzhou, \\ China. Email: yansu@suda.edu.cn.
}

\begin{abstract}
Background: Although advances in the treatment of stage IV gastric cancer (GC) patients, some patients were observed to die within 3 months of initial diagnosis. The present study aimed to explore the early mortality and risk factors for stage IV GC and further develop nomograms.

Methods: A total of 2,174 eligible stage IV GC patients were selected from the Surveillance, Epidemiology, and End Results database. Logistic regression analyses were used to determine the risk factors and develop the nomograms to predict all-cause early death and cancer-specific early death. The predictive performance of the nomograms was assessed by receiver operating characteristic curves (ROC), calibration plots and decision curve analyses (DCA) in both training and validation cohorts.

Results: Of 2,174 patients enrolled, 708 died within 3 months of initial diagnosis ( $\mathrm{n}=668$ for cancerspecific early death). Early mortality remained stable from 2010-2015. Non-Asian or Pacific Islander (API) race, poorer differentiation, middle sites of the stomach, no surgery, no radiotherapy, no chemotherapy, lung metastases and liver metastases were associated with high risk of both all-causes early death and cancerspecific early death. The nomograms constructed based on these factors showed favorable sensitivity, with the area under the ROC range of 0.816-0.847. The calibration curves and DCAs also exhibited adequate fit and ideal net benefit in prediction and clinical application.

Conclusions: Approximately one-third of stage IV GC patients experienced early death. These associated risk factors and predictive nomograms may help clinicians identify the patients at high risk of early death and be the reference for treatment choices.
\end{abstract}

Keywords: Gastric cancer (GC); stage IV; Surveillance, Epidemiology, and End Results (SEER); early death; nomogram

Submitted May 21, 2020. Accepted for publication Aug 05, 2020.

doi: 10.21037/jgo-20-217

View this article at: http://dx.doi.org/10.21037/jgo-20-217

\section{Introduction}

Gastric cancer (GC) ranks as the fifth most frequent malignancy worldwide, with over 1.03 million newly diagnosed GC cases in 2018 (1). More than 30\% of GC patients are diagnosed with synchronous distant metastasis (2). GC patients with distant metastatic disease have the poor prognosis, with the 5 -year survival rate of $<5 \%$ and the median survival of 11-18 months (3-6).

Despite advances in treatment, and the prognosis of GC patients with metastatic disease improving in recent decades (6-9), some GC patients with distant metastatic disease die within 3 months of initial diagnosis. Understanding the risk 


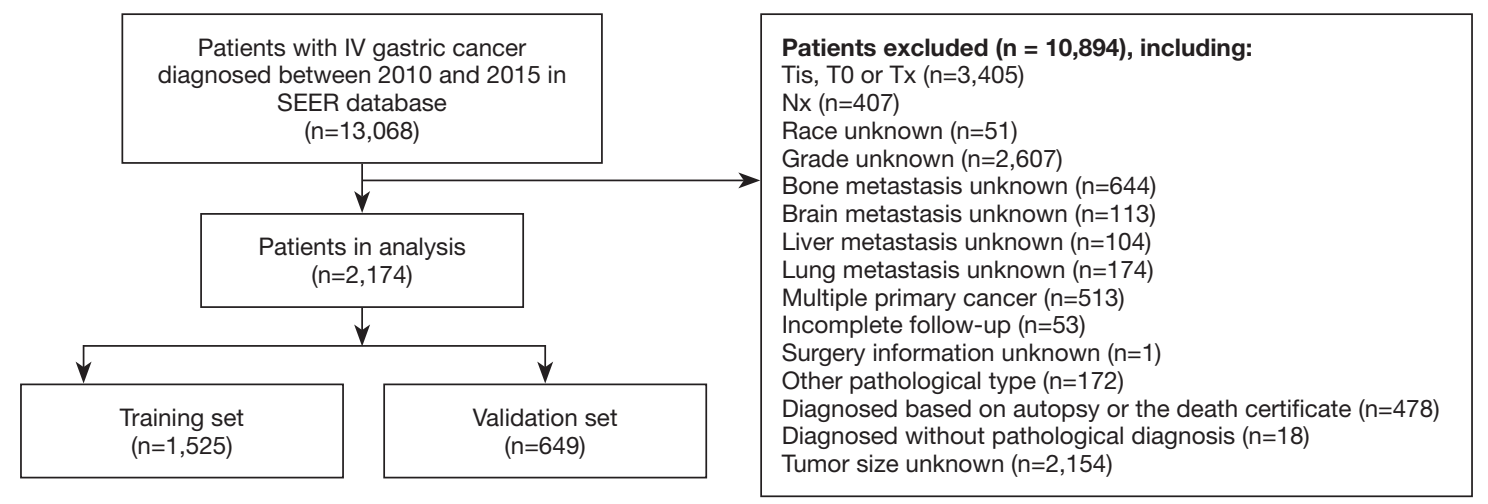

Figure 1 Flowchart of data selection from Surveillance, Epidemiology, and End Results (SEER) database.

factors associated with early mortality for GC patients with distant metastatic disease is crucial, and may assist clinicians in identifying the patients at high risk of early death as well as provide insight into treatment plan options. However, data on early death in GC patients with metastatic disease has not been well documented.

Therefore, in the present study, we used a large population-based database to evaluate the early mortality in GC patients with metastatic disease and identify the risk factors. Furthermore, based on these associated factors, nomograms were developed and validated to predict the risk of early death. We presented the following article in accordance with the TRIPOD reporting checklist (available at http://dx.doi.org/10.21037/jgo-20-217).

\section{Methods}

\section{Database and patient selection}

This was a retrospective study using the Surveillance, Epidemiology, and End Results (SEER) database, which covers more than $28 \%$ of the US population. The stage IV GC patients who were pathologically confirmed diagnosed from 2010 to 2015 were identified in the present study. The International Classification of Diseases for Oncology, 3rd edition (ICD-O-3) was used to limit pathology types (8010 8231, 8255-8576) and tumor sites (C16.0-C16.6, C16.8C16.9). The exclusion criteria were: (I) stage Tis, T0, Tx or NX; (II) unknown histological grade; (III) unknown race; (IV) unknown tumor size; (V) unknown information of distant metastases; (VI) incomplete follow-up; (VII) no primary cancer; (VIII) unknown surgery information; (IX) diagnosed based on autopsy or the death certificate;
(X) other pathological types; (XI) diagnosed without the pathological diagnosis. Finally, 2,174 stage IV GC patients were included in the study and randomly divided into two cohorts (7:3): the training cohort (1,525 patients) and the validation cohort (649 patients). The process for patient selection is shown in Figure 1. The SEER database is an open-access cancer database that only contains de-identified patient data. Therefore, this study was exempted from the approval by the institutional review board of the First Affiliated Hospital of Soochow University.

\section{Variables and definition of early deatb}

Data on patients' demographic characteristics (age at diagnosis, sex, race, and year of diagnosis), tumor and treatment characteristics (tumor grade, histology type, primary tumor site, distant metastatic site, depth of invasion, lymph node metastasis, radiotherapy, chemotherapy, and surgery), and survival data (follow-up time, survival status and cause of death) were included in the analysis. All Patients were followed up for 3 months, or the date of death recorded. Age, as a continuous variable, was divided into three categories $(<50,50-70$ and 270 ). Race was categorized as Asian or Pacific Islander (API) and non-API. We classified primary tumor sites into four groups: cardia (C16.0), middle site (C16.1, C16.2, C16.5 and C16.6), distal site (C16.3 and C16.4), and overlapping or not otherwise specified (NOS) (C16.8 and C16.9). The pathology types were classified into diffuse type (8020-8022, 8142, 8145 and 8490), intestinal type $(8140,8144,8210-8211,8260$ and 8480-8481), and other. The outcomes were all-causes early death and cancer-specific early death. Early death was defined as death within 3 months following the time of initial diagnosis, according to the previous studies (10-12). 


\section{Statistical analysis}

Early mortality among stage IV GC patients was calculated and stratified by year of diagnosis, and metastatic site and number of metastatic organs. Univariate and multivariate logistic regression analyses were used to determine the risk factors in the training cohort. Variables statistically significantly associated with early death on multivariate analyses were used to develop nomograms.

Based on the results of the multivariate logistic regression analyses, two nomograms were developed to separately predict the risk of all-causes and cancer-specific early death. The predictive performance of these nomograms, including their predictive accuracy and calibration, were evaluated in the training and validation cohort. Receiver operating characteristic (ROC) curves were used to measure discrimination. Calibration was assessed graphically by calibration curves, which represented the agreement between observed outcome and predicted probabilities. Decision curve analysis (DCA) was used to evaluate the clinical usefulness in all patients, which quantified the net benefits at different threshold probabilities.

Data was extracted using SEER ${ }^{*}$ Stat software (version 8.3.5; http://seer.cancer.gov/seerstat/). All statistical analyses were performed using R software (version 3.5.2; http:// www.r-project.org) and SPSS statistics software (version 21; IBM Corp, Armonk, NY, USA). Two-tailed P value $<0.05$ was considered as the level for all statistics.

The study was conducted in accordance with the Declaration of Helsinki (as revised in 2013).

\section{Results}

\section{Demographic and clinical characteristics}

According to our inclusion and exclusion criteria (Figure 1), a total of 2,174 eligible patients, who were diagnosed with stage IV GC from 2010 to 2015 in the SEER database, were finally included in the study. The mean age of patients was $63.16 \pm 14.007$ years. Of the patients, $65.32 \%$ of patients $(\mathrm{N}=1,420)$ were male. The most common site of metastasis was the liver (40.57\%), followed by the brain (1.15\%), lungs (12.24\%), and bones (9.48\%). Table 1 shows the patients' characteristics.

\section{Mortality and cause of early death}

Among the 2,174 stage IV GC patients, 708 (32.57\%) experienced all-cause early death. Of these patients, 668 patients had cancer-specific early death and 40 died from non-cancer-related causes (Figure 2A). Patients with noncancer early death died from heart disease $(30.00 \%)$, chronic obstructive pulmonary disease and allied conditions $(10.00 \%)$, cerebrovascular disease $(7.50 \%)$, septicemia $(7.50 \%)$ and diabetes mellitus (5.00\%) (Figure 2B). Allcauses early mortality remained stable between 2010 and 2015 (Figure 3A). All-cause early mortality was highest among patients with brain metastasis $(52.00 \%)$, followed by patients with lung metastasis $(48.87 \%)$, liver metastasis (39.68\%), and bone metastasis (39.32\%) (Figure 3B). The risk of early mortality increased with the number of metastatic organ sites (Figure 3C).

\section{Risk factors for early death}

Using random assignment, 1,525 patients were enrolled into the training cohort and 649 into the validation cohort. The clinical data of these two cohorts are shown in Table 2. According to the univariate logistic regression analyses for the training cohort, advanced age, non-API race, poorer differentiation, middle sites of the stomach, deeper invasion, lymph node metastasis, no surgery, no radiotherapy, no chemotherapy, lung metastases, and liver metastases were significantly associated with all-causes and cancer-specific early death (Table 3). Besides, histological type was also observed to be significantly associated with cancer-specific early death (Table 3). These risk factors associated with allcauses and cancer-specific early mortality, identified in the univariate logistic regression analyses, were included in the multivariate logistic analyses, which found that non-API race, poorer differentiation, middle sites of the stomach, no surgery, no radiotherapy, no chemotherapy, lung metastases, and liver metastases were significantly associated with allcause and cancer-specific early death (Table 4).

\section{Nomogram development}

Based on the results of the multivariate logistic analyses, two nomograms were developed to predict the risk of allcauses early death (Figure 4A) and cancer-specific early death (Figure 4B). The relative risk score for each risk factor is shown in Table 5. The steps for using the nomograms are as follows: (I) draw a straight line upwards from each predictor to the top point reference line to determine the patient's value; (II) tally up the predictive variables points; and (III) locate the final score on the total points reference line, draw a straight line to the bottom probability line 
Table 1 The early death in patients with stage IV gastric cancer

\begin{tabular}{|c|c|c|c|c|c|c|c|c|c|c|}
\hline \multirow{2}{*}{ Characters } & \multicolumn{2}{|c|}{$\begin{array}{l}\text { Total patients } \\
(\mathrm{n}=2,174)\end{array}$} & \multicolumn{2}{|c|}{$\begin{array}{l}\text { No early death } \\
\quad(n=1,466)\end{array}$} & \multicolumn{2}{|c|}{$\begin{array}{l}\text { All-cause early death } \\
\qquad(\mathrm{n}=708)\end{array}$} & \multicolumn{2}{|c|}{$\begin{array}{l}\text { Cancer-specific early } \\
\text { death }(n=668)\end{array}$} & \multicolumn{2}{|c|}{$\begin{array}{l}\text { Non-cancer-specific } \\
\text { early death }(n=40)\end{array}$} \\
\hline & $\begin{array}{l}\text { No. of } \\
\text { patients }\end{array}$ & $\%$ & $\begin{array}{l}\text { No. of } \\
\text { patients }\end{array}$ & $\%$ & $\begin{array}{c}\text { No. of } \\
\text { patients }\end{array}$ & $\%$ & $\begin{array}{c}\text { No. of } \\
\text { patients }\end{array}$ & $\%$ & $\begin{array}{l}\text { No. of } \\
\text { patients }\end{array}$ & $\%$ \\
\hline \multicolumn{11}{|l|}{ Age (years) } \\
\hline$<50$ & 360 & 16.56 & 282 & 19.24 & 78 & 11.02 & 73 & 10.93 & 5 & 12.50 \\
\hline$\geq 70$ & 752 & 34.59 & 417 & 28.44 & 335 & 47.32 & 317 & 47.46 & 18 & 45.00 \\
\hline \multicolumn{11}{|l|}{ Sex } \\
\hline Male & 1,420 & 65.32 & 953 & 65.01 & 467 & 65.96 & 440 & 65.87 & 27 & 67.50 \\
\hline Female & 754 & 34.68 & 513 & 34.99 & 241 & 34.04 & 228 & 34.13 & 13 & 32.50 \\
\hline API & 333 & 15.32 & 241 & 16.44 & 92 & 12.99 & 90 & 13.47 & 2 & 5.00 \\
\hline \multicolumn{11}{|l|}{ Size } \\
\hline$<1 \mathrm{~cm}$ & 19 & 0.87 & 14 & 0.95 & 5 & 0.71 & 5 & 0.75 & 0 & 0.00 \\
\hline $1-2 \mathrm{~cm}$ & 95 & 4.37 & 60 & 4.09 & 35 & 4.94 & 34 & 5.09 & 1 & 2.50 \\
\hline $2-3 \mathrm{~cm}$ & 165 & 7.59 & 120 & 8.19 & 45 & 6.36 & 43 & 6.44 & 2 & 5.00 \\
\hline $3-4 \mathrm{~cm}$ & 273 & 12.56 & 191 & 13.03 & 82 & 11.58 & 76 & 11.38 & 6 & 15.00 \\
\hline $4-5 \mathrm{~cm}$ & 305 & 14.03 & 204 & 13.92 & 101 & 14.27 & 94 & 14.07 & 7 & 17.50 \\
\hline Non-differentiated & 51 & 2.35 & 30 & 2.05 & 21 & 2.97 & 19 & 2.84 & 2 & 5.00 \\
\hline \multicolumn{11}{|l|}{ Tumor subsites } \\
\hline Cardia & 729 & 33.53 & 525 & 35.81 & 204 & 28.81 & 188 & 28.14 & 16 & 40.00 \\
\hline Middle & 586 & 26.95 & 378 & 25.78 & 208 & 29.38 & 195 & 29.19 & 13 & 32.50 \\
\hline Distal & 433 & 19.92 & 287 & 19.58 & 146 & 20.62 & 143 & 21.41 & 3 & 7.50 \\
\hline Overlapping/NOS & 426 & 19.60 & 276 & 18.83 & 150 & 21.19 & 142 & 21.26 & 8 & 20.00 \\
\hline \multicolumn{11}{|l|}{ Histological type } \\
\hline Diffuse & 567 & 26.08 & 399 & 27.22 & 168 & 23.73 & 159 & 23.80 & 9 & 22.50 \\
\hline Intestinal & 1,462 & 67.25 & 976 & 66.58 & 486 & 68.64 & 457 & 68.41 & 29 & 72.50 \\
\hline Other & 145 & 6.67 & 91 & 6.21 & 54 & 7.63 & 52 & 7.78 & 2 & 5.00 \\
\hline
\end{tabular}

Table 1 (continued) 
Table 1 (continued)

\begin{tabular}{|c|c|c|c|c|c|c|c|c|c|c|}
\hline \multirow{2}{*}{ Characters } & \multicolumn{2}{|c|}{$\begin{array}{l}\text { Total patients } \\
\qquad(\mathrm{n}=2,174)\end{array}$} & \multicolumn{2}{|c|}{$\begin{array}{l}\text { No early death } \\
\quad(n=1,466)\end{array}$} & \multicolumn{2}{|c|}{$\begin{array}{l}\text { All-cause early death } \\
\qquad(\mathrm{n}=708)\end{array}$} & \multicolumn{2}{|c|}{$\begin{array}{c}\text { Cancer-specific early } \\
\text { death }(n=668)\end{array}$} & \multicolumn{2}{|c|}{$\begin{array}{c}\text { Non-cancer-specific } \\
\text { early death }(n=40)\end{array}$} \\
\hline & $\begin{array}{c}\text { No. of } \\
\text { patients }\end{array}$ & $\%$ & $\begin{array}{c}\text { No. of } \\
\text { patients }\end{array}$ & $\%$ & $\begin{array}{l}\text { No. of } \\
\text { patients }\end{array}$ & $\%$ & $\begin{array}{l}\text { No. of } \\
\text { patients }\end{array}$ & $\%$ & $\begin{array}{c}\text { No. of } \\
\text { patients }\end{array}$ & $\%$ \\
\hline \multicolumn{11}{|c|}{ Depth of invasion } \\
\hline $\mathrm{T} 1, \mathrm{~T} 2$ & 689 & 31.69 & 437 & 29.81 & 252 & 30.59 & 235 & 35.18 & 17 & 42.50 \\
\hline \multicolumn{11}{|c|}{ Lymph node metastasis } \\
\hline No & 648 & 29.81 & 385 & 26.26 & 263 & 37.15 & 247 & 36.98 & 16 & 40.00 \\
\hline $\mathrm{N} 1$ & 869 & 39.97 & 581 & 39.63 & 288 & 40.68 & 269 & 40.27 & 19 & 47.50 \\
\hline $\mathrm{N} 2$ & 272 & 12.51 & 209 & 14.26 & 63 & 8.90 & 62 & 9.28 & 1 & 2.50 \\
\hline No & 1,451 & 66.74 & 902 & 61.53 & 549 & 77.54 & 519 & 77.69 & 30 & 75.00 \\
\hline Yes & 723 & 33.26 & 564 & 38.47 & 159 & 22.46 & 149 & 22.31 & 10 & 25.00 \\
\hline \multicolumn{11}{|c|}{ Radiotherapy } \\
\hline No & 1,697 & 78.06 & 1,084 & 73.94 & 613 & 86.58 & 579 & 86.68 & 34 & 85.00 \\
\hline Yes & 477 & 21.94 & 382 & 26.06 & 95 & 13.42 & 89 & 13.32 & 6 & 15.00 \\
\hline \multicolumn{11}{|c|}{ Chemotherapy } \\
\hline No & 748 & 34.41 & 255 & 17.39 & 493 & 69.63 & 463 & 69.31 & 30 & 75.00 \\
\hline No & 1,968 & 90.52 & 1,341 & 91.47 & 627 & 88.56 & 591 & 88.47 & 36 & 90.00 \\
\hline Yes & 206 & 9.48 & 125 & 8.53 & 81 & 11.44 & 77 & 11.53 & 4 & 10.00 \\
\hline \multicolumn{11}{|c|}{ Lung metastases } \\
\hline No & 1,908 & 87.76 & 1,330 & 90.72 & 578 & 81.64 & 546 & 81.74 & 32 & 80.00 \\
\hline Yes & 266 & 12.24 & 136 & 9.28 & 130 & 18.36 & 122 & 18.26 & 8 & 20.00 \\
\hline \multicolumn{11}{|c|}{ Liver metastases } \\
\hline No & 1,292 & 59.43 & 934 & 63.71 & 358 & 50.56 & 335 & 50.15 & 23 & 57.50 \\
\hline Yes & 882 & 40.57 & 532 & 36.29 & 350 & 49.44 & 333 & 49.85 & 17 & 42.50 \\
\hline
\end{tabular}


A

$30.73 \%$

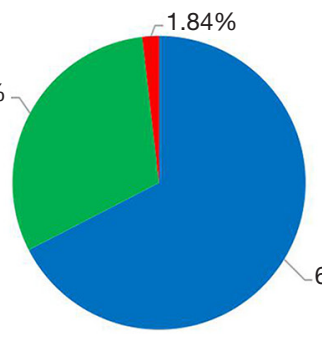

॥ No early death

- Cancer-specific early death

- Non-cancer- specific early death
B

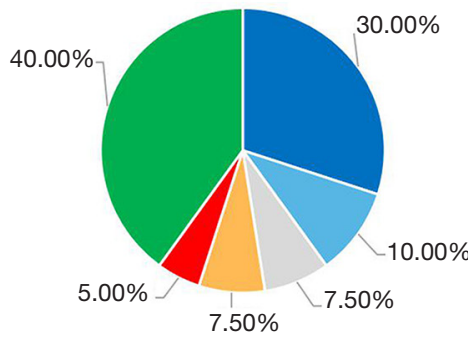

- Diseases of Heart

Chronic Obstructive Pulmonary

"Disease and Allied Cond

Cerebrovascular Diseases

- Septicemia

- Diabetes Mellitus

- Other Cause of Death

Figure 2 Distribution of the incidence of cancer-specific early death (A) and all-cause early death (B) among stage IV gastric cancer patients.

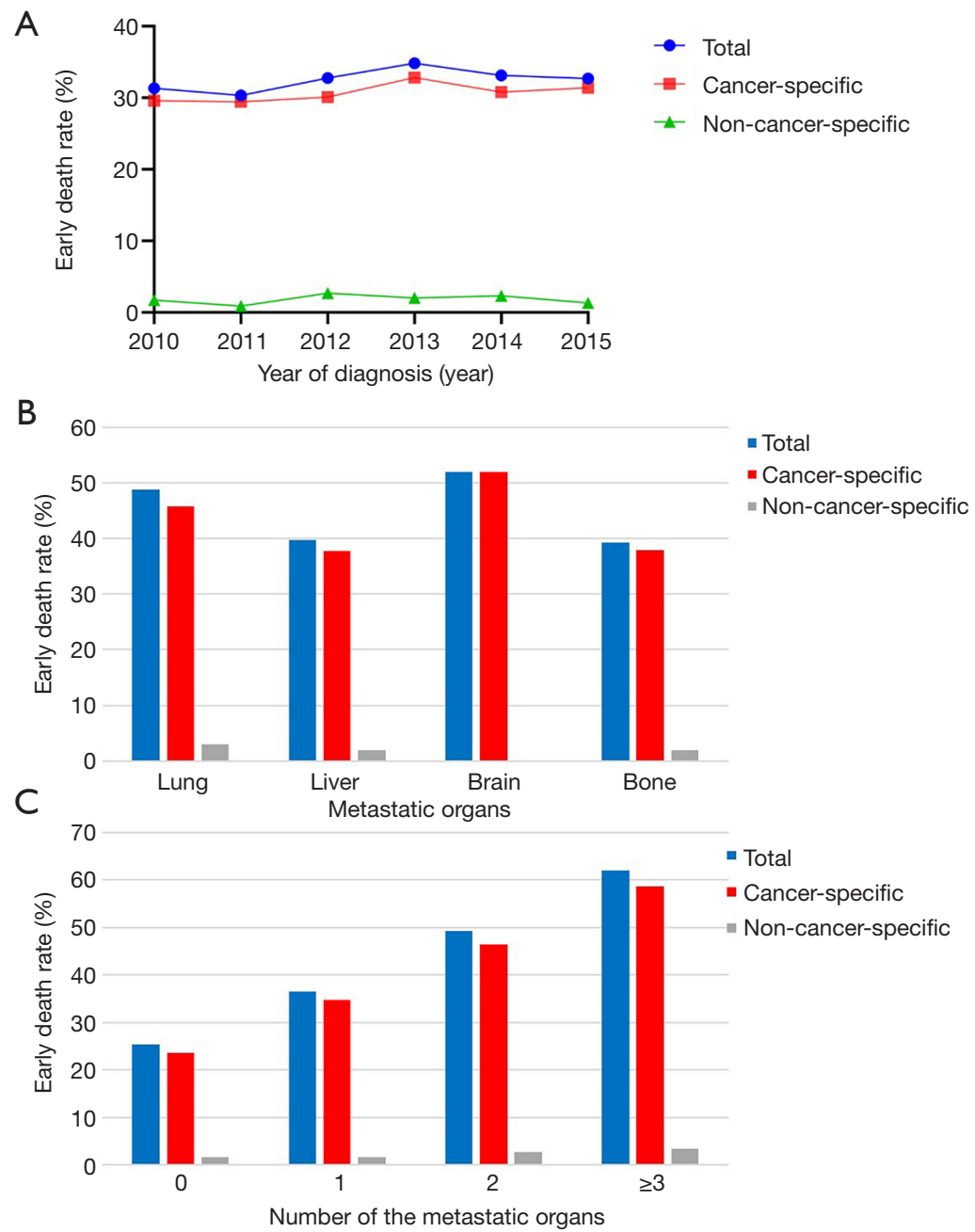

Figure 3 Distribution of early death among stage IV gastric cancer patients stratified by year of diagnosis (A), metastatic site (B) and number of the metastatic organs $(\mathrm{C})$. 
Table 2 The baseline characteristics of the training and validation cohorts

\begin{tabular}{|c|c|c|c|c|}
\hline \multirow{2}{*}{ Characteristics } & \multicolumn{2}{|c|}{ Training cohort $(n=1,525)$} & \multicolumn{2}{|c|}{ Validation cohort $(n=649)$} \\
\hline & No. of patients & $\%$ & No. of patients & $\%$ \\
\hline \multicolumn{5}{|l|}{ Age (years) } \\
\hline$<50$ & 257 & 16.85 & 103 & 15.87 \\
\hline $50-70$ & 757 & 49.64 & 305 & 47.00 \\
\hline \multicolumn{5}{|l|}{ Sex } \\
\hline Male & 1,003 & 65.77 & 417 & 64.25 \\
\hline Female & 522 & 34.23 & 232 & 35.75 \\
\hline \multicolumn{5}{|l|}{ Race } \\
\hline \multicolumn{5}{|l|}{ Size } \\
\hline$<1 \mathrm{~cm}$ & 15 & 0.98 & 4 & 0.62 \\
\hline $1-2 \mathrm{~cm}$ & 71 & 4.66 & 24 & 3.70 \\
\hline $2-3 \mathrm{~cm}$ & 116 & 7.61 & 49 & 7.55 \\
\hline $3-4 \mathrm{~cm}$ & 196 & 12.85 & 77 & 11.86 \\
\hline $4-5 \mathrm{~cm}$ & 207 & 13.57 & 98 & 15.10 \\
\hline$\geq 5 \mathrm{~cm}$ & 920 & 60.33 & 397 & 61.17 \\
\hline \multicolumn{5}{|l|}{ Differentiation } \\
\hline Cardia & 497 & 32.59 & 232 & 35.75 \\
\hline Middle & 419 & 27.48 & 167 & 25.73 \\
\hline Distal & 299 & 19.61 & 134 & 20.65 \\
\hline Overlapping/NOS & 310 & 20.33 & 116 & 17.87 \\
\hline \multicolumn{5}{|l|}{ Histological type } \\
\hline Diffuse & 407 & 26.69 & 160 & 24.65 \\
\hline Intestinal & 1,016 & 66.62 & 446 & 68.72 \\
\hline Other & 102 & 6.69 & 43 & 6.63 \\
\hline \multicolumn{5}{|l|}{ Depth of invasion } \\
\hline $\mathrm{T} 1, \mathrm{~T} 2$ & 481 & 31.54 & 208 & 32.05 \\
\hline $\mathrm{T} 3, \mathrm{~T} 4$ & 1,044 & 68.46 & 441 & 67.95 \\
\hline
\end{tabular}

Table 2 (continued) 
Table 2 (continued)

\begin{tabular}{|c|c|c|c|c|}
\hline Characteristics & \multicolumn{2}{|c|}{ Training cohort $(n=1,525)$} & \multicolumn{2}{|c|}{ Validation cohort $(n=649)$} \\
\hline \multicolumn{5}{|c|}{ Lymph node metastasis } \\
\hline No & 443 & 29.05 & 205 & 31.59 \\
\hline N1 & 623 & 40.85 & 246 & 37.90 \\
\hline N3 & 267 & 17.51 & 118 & 18.18 \\
\hline \multicolumn{5}{|l|}{ Surgery } \\
\hline No & 1,023 & 67.08 & 428 & 65.95 \\
\hline Yes & 502 & 32.92 & 221 & 34.05 \\
\hline Yes & 333 & 21.84 & 144 & 22.19 \\
\hline \multicolumn{5}{|l|}{ Chemotherapy } \\
\hline No & 520 & 34.10 & 228 & 35.13 \\
\hline Yes & 1,005 & 65.90 & 421 & 64.87 \\
\hline \multicolumn{5}{|l|}{ Brain metastases } \\
\hline No & 1,507 & 98.82 & 642 & 98.92 \\
\hline Yes & 18 & 1.18 & 7 & 1.08 \\
\hline \multicolumn{5}{|c|}{ Bone metastases } \\
\hline \multicolumn{5}{|l|}{ Liver metastases } \\
\hline No & 907 & 59.48 & 385 & 59.32 \\
\hline Yes & 618 & 40.52 & 264 & 40.68 \\
\hline
\end{tabular}

API, Asian or Pacific Islander.

to determine the patient's likelihood of metastasis. The prediction websites of the nomograms predicting the risk of all-causes of early death and cancer-specific early death are https://yyangyi.shinyapps.io/IVGC_ED_AC/ and https:// yyangyi.shinyapps.io/IVGC_ED_CS/.

\section{Nomogram evaluation}

The area under the ROC curve (AUC) for the nomograms to separately predict the risk of all-causes early death and cancer-specific early death were 0.847 and 0.825 , respectively, in the training cohort, and 0.835 and 0.816 , respectively, in the validation cohort (Figure 5). Calibration curves for the two nomograms showed great agreement between predictions and observations in both training cohort and validation cohort (Figure 6). Additionally, the DCAs exhibited the ideal net benefits for all patients when predicting all-causes early death and cancer-specific early 
Table 3 Univariate logistic regression for analyzing the risk factors for early death

\begin{tabular}{|c|c|c|c|c|c|c|}
\hline Variable & \multicolumn{3}{|c|}{ All-cause early death } & \multicolumn{3}{|c|}{ Cancer-specific early death } \\
\hline \multicolumn{7}{|l|}{ Age (years) } \\
\hline$<50$ & 1 (ref.) & & & 1 (ref.) & & \\
\hline $50-70$ & 1.230 & $0.882-1.714$ & 0.223 & 1.228 & $0.876-1.723$ & 0.234 \\
\hline \multicolumn{7}{|l|}{ Sex } \\
\hline Male & 1 (ref.) & & & 1 (ref.) & & \\
\hline Female & 0.93 & $0.741-1.167$ & 0.532 & 0.897 & $0.712-1.131$ & 0.358 \\
\hline \multicolumn{7}{|l|}{ Race } \\
\hline \multicolumn{7}{|l|}{ Size } \\
\hline$<1 \mathrm{~cm}$ & 1 (ref.) & & & 1 (ref.) & & \\
\hline $1-2 \mathrm{~cm}$ & 1.495 & $0.431-5.184$ & 0.527 & 1.404 & $0.404-4.880$ & 0.593 \\
\hline $2-3 \mathrm{~cm}$ & 1.093 & $0.325-3.679$ & 0.885 & 1.003 & $0.297-3.384$ & 0.996 \\
\hline $3-4 \mathrm{~cm}$ & 1.243 & $0.380-4.059$ & 0.719 & 1.128 & $0.345-3.689$ & 0.842 \\
\hline $4-5 \mathrm{~cm}$ & 1.316 & $0.404-4.287$ & 0.648 & 1.231 & $0.378-4.012$ & 0.731 \\
\hline$\geq 5 \mathrm{~cm}$ & 1.344 & $0.424-4.255$ & 0.615 & 1.247 & $0.394-3.949$ & 0.708 \\
\hline \multicolumn{7}{|l|}{ Differentiation } \\
\hline Cardia & 1 (ref.) & & & 1 (ref.) & & \\
\hline Middle & 1.451 & $1.096-1.919$ & 0.009 & 1.417 & $1.066-1.883$ & 0.016 \\
\hline Distal & 1.174 & $0.858-1.607$ & 0.315 & 1.203 & $0.876-1.653$ & 0.254 \\
\hline Overlapping/NOS & 1.451 & $1.071-1.967$ & 0.016 & 1.431 & $1.051-1.948$ & 0.023 \\
\hline \multicolumn{7}{|l|}{ Histological type } \\
\hline Diffuse & 1 (ref.) & & & 1 (ref.) & & \\
\hline Intestinal & 1.083 & $0.845-1.389$ & 0.529 & 1.07 & $0.832-1.378$ & 0.597 \\
\hline Other & 1.534 & $0.979-2.402$ & 0.062 & 1.58 & $1.006-2.482$ & 0.047 \\
\hline \multicolumn{7}{|l|}{ Depth of invasion } \\
\hline $\mathrm{T} 1, \mathrm{~T} 2$ & 1 (ref.) & & & 1 (ref.) & & \\
\hline T3, T4 & 0.713 & $0.568-0.895$ & 0.004 & 0.717 & $0.570-0.903$ & 0.005 \\
\hline
\end{tabular}

Table 3 (continued) 
Table 3 (continued)

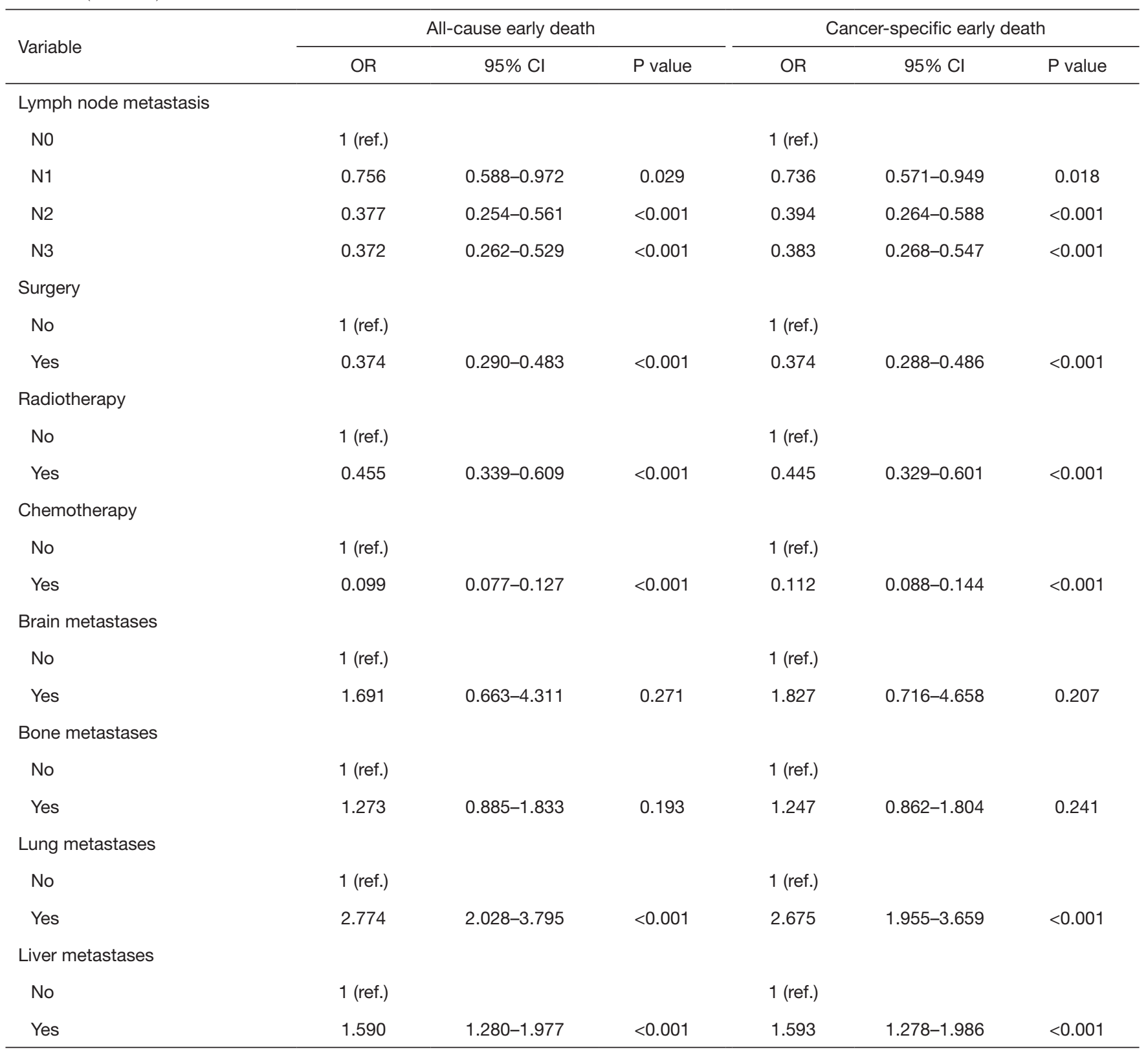

OR, odds ratio; ref., reference; API, Asian or Pacific Islander.

death, which showed that these nomograms had favorable clinical value (Figure 7).

\section{Discussion}

GC is a major cause of cancer mortality worldwide (1), and the clinical stage is one of the key factors affecting the prognosis (13-15). Although many previous studies have investigated the prognosis of patients with stage IV GC (9,16-19), little is known about early death. To the best of our knowledge, the present study is the first to explore the early mortality and associated factors among stage IV GC patients.

In the present study, we observed that $32.57 \%$ stage IV GC patients died within 3 months after the initial diagnosis, and most of these deaths were cancer specific. 
Table 4 Multivariate logistic regression for analyzing the risk factors for early death

\begin{tabular}{|c|c|c|c|c|c|c|}
\hline Variable & \multicolumn{3}{|c|}{ All-cause early death } & \multicolumn{3}{|c|}{ Cancer-specific early death } \\
\hline \multicolumn{7}{|l|}{ Age (years) } \\
\hline$<50$ & 1 (ref.) & & & 1 (ref.) & & \\
\hline $50-70$ & 0.814 & $0.544-1.217$ & 0.316 & 0.835 & $0.557-1.252$ & 0.384 \\
\hline \multicolumn{7}{|l|}{ Race } \\
\hline Non-API & 1 (ref.) & & & 1 (ref.) & & \\
\hline API & 0.606 & $0.401-0.915$ & 0.017 & 0.666 & $0.444-1.000$ & 0.050 \\
\hline \multicolumn{7}{|l|}{ Differentiation } \\
\hline Poorly differentiated & 4.333 & $1.480-12.683$ & 0.007 & 3.588 & $1.250-10.298$ & 0.018 \\
\hline Non-differentiated & 9.665 & $2.551-36.611$ & 0.001 & 7.294 & $1.968-27.027$ & 0.003 \\
\hline \multicolumn{7}{|l|}{ Tumor subsites } \\
\hline Cardia & 1 (ref.) & & & 1 (ref.) & & \\
\hline Middle & 1.620 & $1.125-2.332$ & 0.009 & 1.539 & $1.071-2.213$ & 0.020 \\
\hline Distal & 1.433 & $0.924-2.221$ & 0.108 & 1.467 & $0.949-2.266$ & 0.084 \\
\hline Overlapping/NOS & 1.675 & $1.113-2.522$ & 0.013 & 1.597 & $1.060-2.405$ & 0.025 \\
\hline \multicolumn{7}{|l|}{ Histological type } \\
\hline $\mathrm{T} 1, \mathrm{~T} 2$ & 1 (ref.) & & & 1 (ref.) & & \\
\hline $\mathrm{T} 3, \mathrm{~T} 4$ & 1.12 & $0.819-1.531$ & 0.477 & 1.111 & $0.815-1.515$ & 0.506 \\
\hline \multicolumn{7}{|l|}{ Lymph node metastasis } \\
\hline NO & 1 (ref.) & & & 1 (ref.) & & \\
\hline N1 & 0.947 & $0.687-1.306$ & 0.742 & 0.895 & $0.651-1.230$ & 0.495 \\
\hline N2 & 0.836 & $0.504-1.386$ & 0.487 & 0.873 & $0.529-1.441$ & 0.595 \\
\hline N3 & 0.769 & $0.474-1.250$ & 0.290 & 0.817 & $0.504-1.326$ & 0.414 \\
\hline \multicolumn{7}{|l|}{ Surgery } \\
\hline No & 1 (ref.) & & & 1 (ref.) & & \\
\hline Yes & 0.22 & $0.147-0.329$ & $<0.001$ & 0.226 & $0.151-0.337$ & $<0.001$ \\
\hline
\end{tabular}

Table 4 (continued) 
Table 4 (continued)

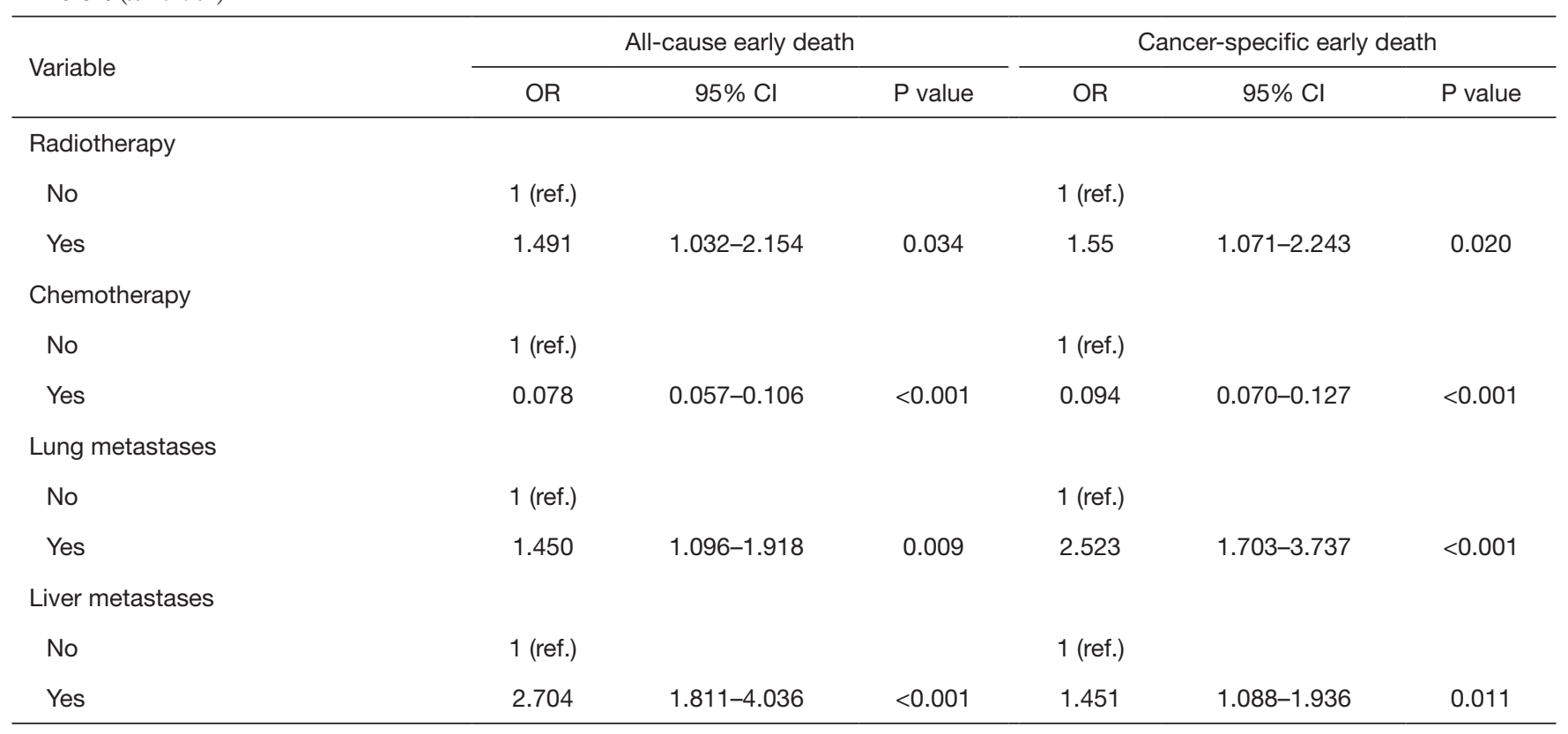

OR, odds ratio; ref., reference; API, Asian or Pacific Islander.

Only $1.84 \%$ of early deaths were not cancer-specific, with heart disease being the main cause of non-cancer early death. This finding is in agreement with a Swedish study by Xie et al., which found that disease of heart was one of the major causes of non-cancer death (20). Similar results have also been observed in other types of cancer, such as liver cancer, bladder cancer and breast cancer (21-24). In a recent study, Herrmann found that heart disease often occurred in the first year after the initial diagnosis (25). This might be due to the interaction between the acute cancer phase and pre-existing cardiovascular (CV) diseases, including $\mathrm{CV}$ risk associated with the tumor burden and potential $\mathrm{CV}$ toxicities of cancer therapies (25). These findings may suggest that the monitoring of heart disease in patients with stage IV GC should be improved.

We found that the early mortality of stage IV GC patients increased with the number of metastatic organ sites. Zhang et al. reported a similar result in GC (26). The similar result was also observed in other tumors $(12,27)$. The prognostic significance of the number of metastatic organ sites has been linked to resistance among patients with a larger tumor burden (28). However, the SEER database only contains information on liver, lung, bone, and brain metastatic sites, and the lack of data on other metastatic sites may impair the accuracy of our findings. Therefore, our results are only preliminary and need to be interpreted with caution. Futures studies with larger sample sizes are warranted.

Although the prognosis of GC patients has been improved in recent years $(8,9)$, we found that the early mortality remained stable during 2010-2015, which suggests that we need to pay more attention to early death and its related factors to reduce the risk of early death. Several characteristics and treatment modalities were found to be independent risk factors associated with all-cause early death and cancer-specific early death in our study, including non-API, poorer differentiation, middle sites of stomach, lung metastases, liver metastases, no surgery, no radiotherapy, and no chemotherapy.

We found that API races had a lower risk of death compared to other race, which has also been proved in many earlier studies (29-31). Jin et al. indicated that regular screening and earlier diagnosis among the API population might partially account for this survival advantage (32). Compared to patients of other races, API patients were considered to have a more positive attitude toward treatment $(33,34)$. Zhang et al. and Ulanja et al. reported that the API had a higher rate of surgery and radiation than patients of other races $(33,34)$. Aggressive treatment could effectively reduce the risk of early death (18). More researches are needed to explore the reasons behind survival differences between different races in the future. 


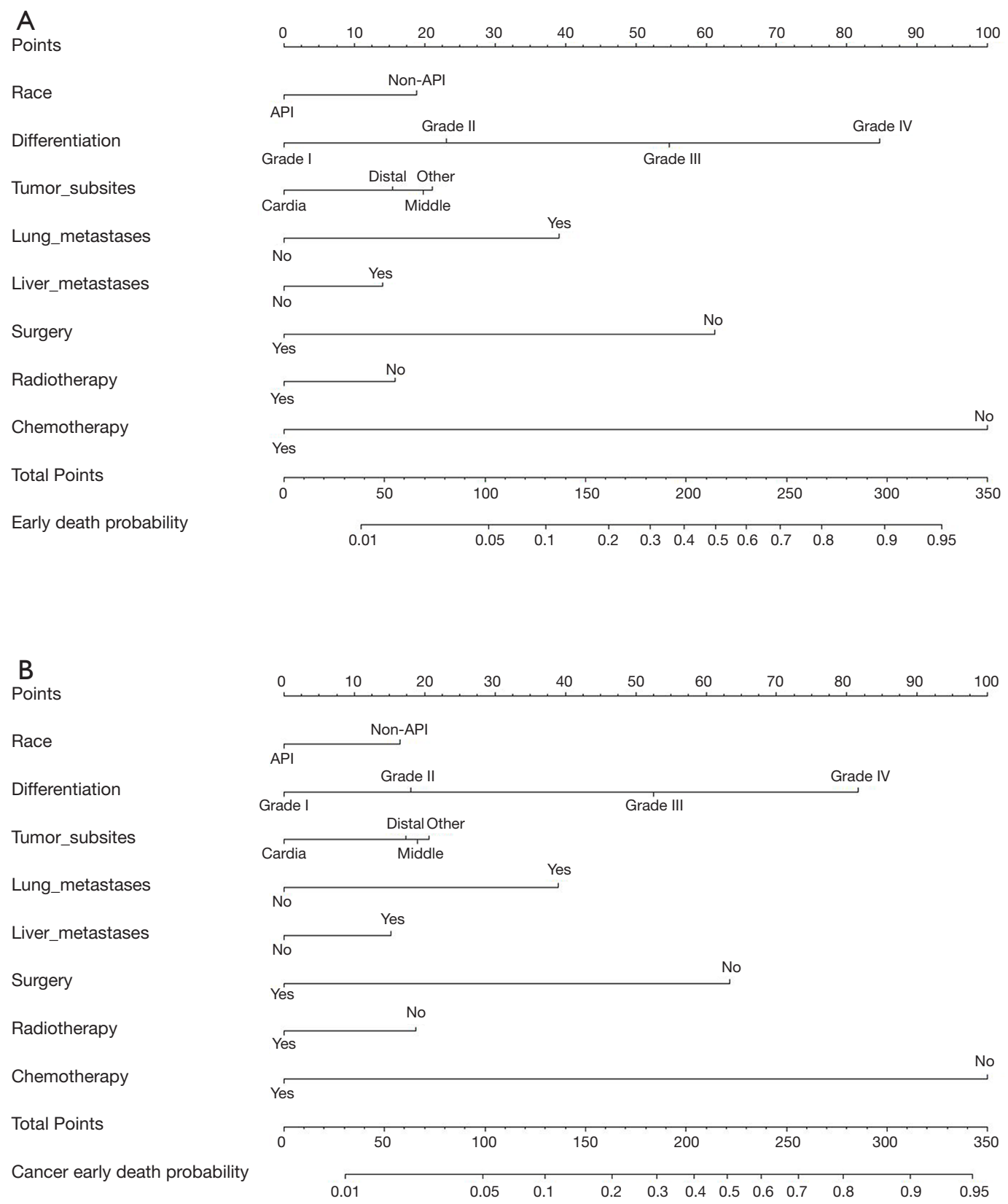

Figure 4 Nomograms for predicting all-causes (A) and cancer-specific early death (B). Other, overlapping/NOS.

The impact of surgery on the prognosis of stage IV GC patients remains controversial (3,35-39). Previous studies have reported that patients with stage IV GC could have survival benefit from the surgery (36-38). The disadvantages of surgery that can seriously affect survival, including chemotherapy delay and the increased risk of surgical-related complications, also need to be considered.
The findings of the present study showed that patients who had undergone surgery could have potential survival benefits and a lower risk of early death, even with the risk of postoperative complications. However, as our study was retrospective, selection bias could exist. More prospective researches are needed to confirm this conclusion in the future. 
Table 5 Point assignments and predictive scores for each variable in two nomograms

\begin{tabular}{|c|c|c|c|c|}
\hline Variables & \multicolumn{2}{|c|}{ All-cause early death } & \multicolumn{2}{|c|}{ Cancer-specific early death } \\
\hline \multirow[t]{2}{*}{ Race } & API & 0 & $\mathrm{API}$ & 0 \\
\hline & Non-API & 19 & Non-API & 17 \\
\hline \multirow[t]{3}{*}{ Differentiation } & Grade I & 0 & Grade I & 0 \\
\hline & Grade III & 55 & Grade III & 53 \\
\hline & Grade IV & 85 & Grade IV & 82 \\
\hline \multirow[t]{2}{*}{ Tumor subsites } & Cardia & 0 & Cardia & 0 \\
\hline & Distal & 15 & Distal & 17 \\
\hline \multirow[t]{2}{*}{ Lung metastases } & No & 0 & No & 0 \\
\hline & Yes & 39 & Yes & 39 \\
\hline \multirow[t]{2}{*}{ Liver metastases } & No & 0 & No & 0 \\
\hline & Yes & 14 & Yes & 15 \\
\hline \multirow[t]{2}{*}{ Surgery } & No & 61 & No & 63 \\
\hline & Yes & 0 & Yes & 0 \\
\hline \multirow[t]{2}{*}{ Radiotherapy } & No & 16 & No & 19 \\
\hline & Yes & 0 & Yes & 0 \\
\hline
\end{tabular}

In addition to race and surgery, other factors were also reported to be associated with prognosis in the previous studies $(17,40)$. Ma et al. developed a nomogram to predict survival in patients with metastatic gastric adenocarcinoma who underwent palliative gastrectomy, based on age, tumor size, location, tumor grade, $\mathrm{T}$ stage, $\mathrm{N}$ stage, metastatic site, scope of gastrectomy, number of examined lymph nodes, chemotherapy, and radiotherapy (17). Gao et al. developed a nomogram for prediction of stage III/IV GC outcome after surgery based on the tumor size, age, $\mathrm{N}$ stage, tumor grade, and distant metastases (41). Some variables included in the nomograms in previous study were not statistically significant on multivariate analysis in our study, including age. Although age was an important clinical prognostic factor for patients with stage IV GC after surgery in the two previously mentioned studies, some studies found that age is not an independently associated factor for cancer- specific mortality in patients with stage IV GC (42). Differences among these results could be due to relatively higher perioperative mortality of the elder patients after the surgical treatment. The applicable people and the outcome which nomograms in previous studies were fit for and used to predict were different from our study, which may lead to the difference of risk factors. Considering these different variables have not been identified to be associated with the early death in GC, we did not include these variables in our nomograms.

Although several previous studies have constructed nomograms to predict the prognosis of patients with stage IV GC $(17,40,41,43,44)$, to the best of our knowledge, no studies have developed nomograms to predict early death in patients with stage IV GC. In the present study, we developed two nomograms to predict the risk of allcause early death and cancer-specific early death. These 
A

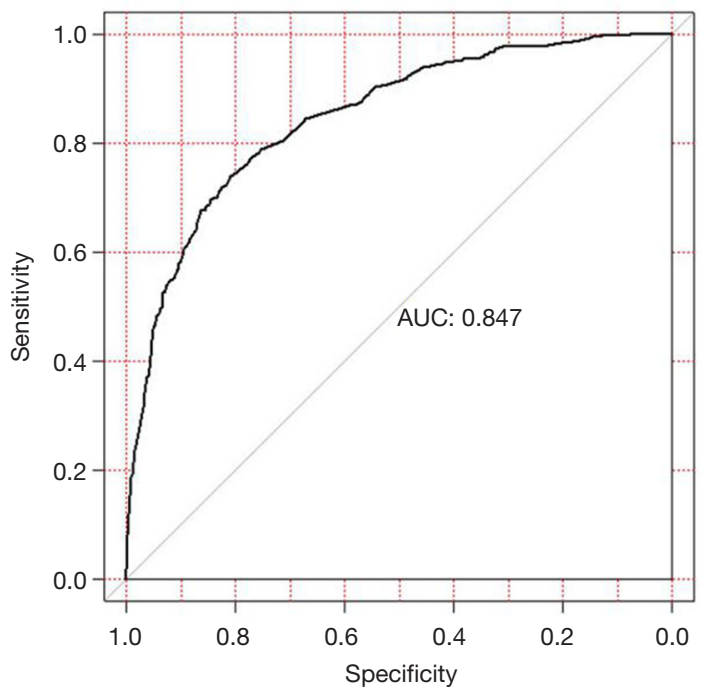

C

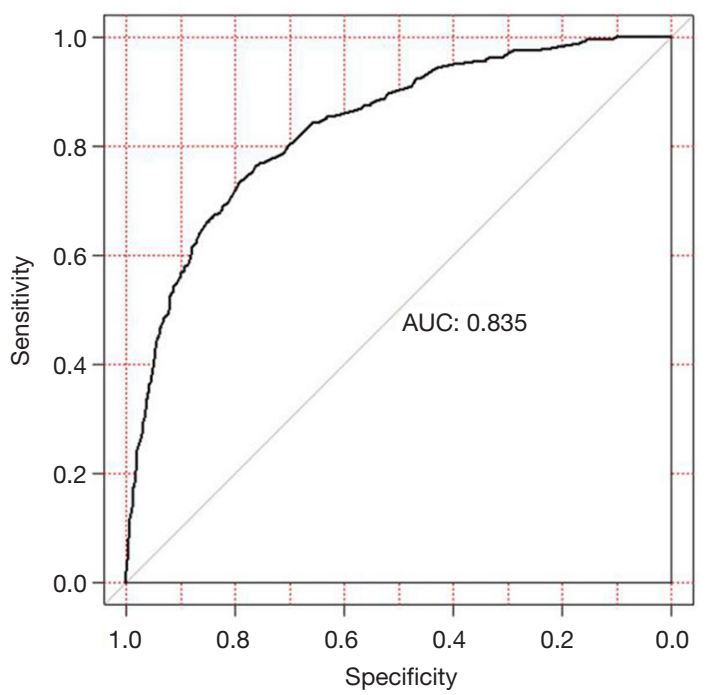

B

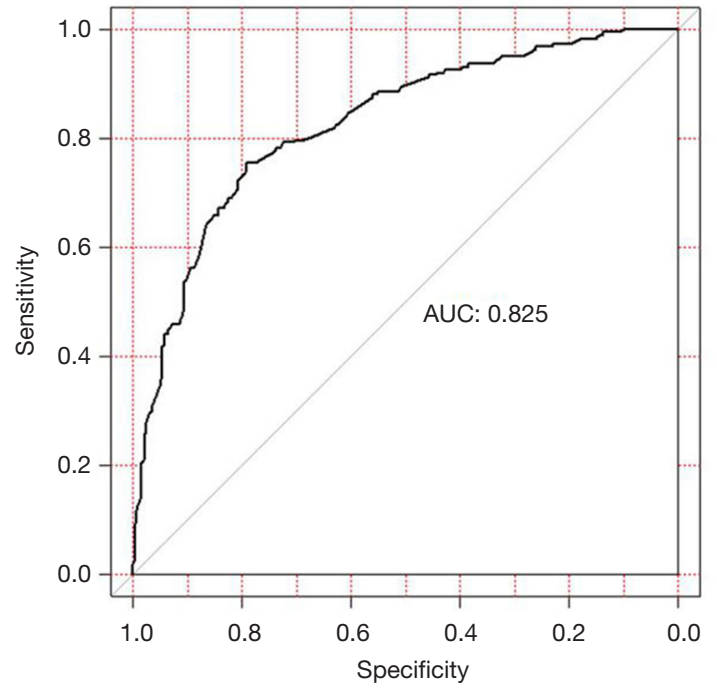

D

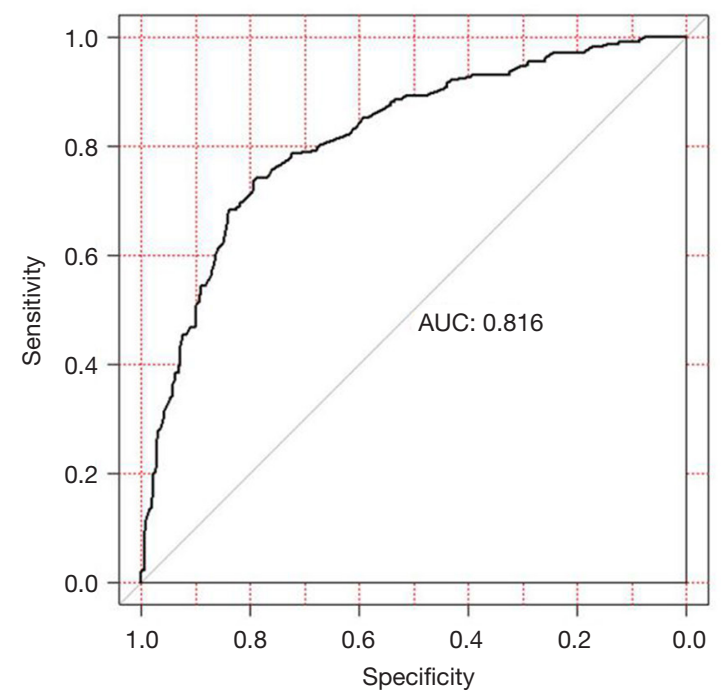

Figure 5 Receiver operating characteristic (ROC) curves for discrimination of the nomograms in predicting all-causes and cancer-specific early death in the training cohort (A, B) and the validation cohort (C, D).

nomograms were evaluated in the training and validation cohorts. Taking into account the AUCs and the calibration plots in the training and validation cohorts, these nomograms showed reliable discrimination and calibration ability. Moreover, these nomograms also showed good clinical value, as indicated by DCAs.

These nomograms are quantitative and intuitive, which are convenient to use. These simple-to-use nomograms can be used to predict real-time risk of early death in GC patients, including the patients not receiving any treatment at the time of diagnosis and patients who were currently receiving treatment. The predicted risk of early death is changed with the current treatments. Besides, these nomograms can be used to predict the risk of early death of patients if they will receive some treatments, which can assist in determining suitable treatment options. These nomograms can also improve communication of prognosis with patients and enable informed decision making. In addition, these nomograms can provide insight into the disease management and be the reference for the follow-up 
A

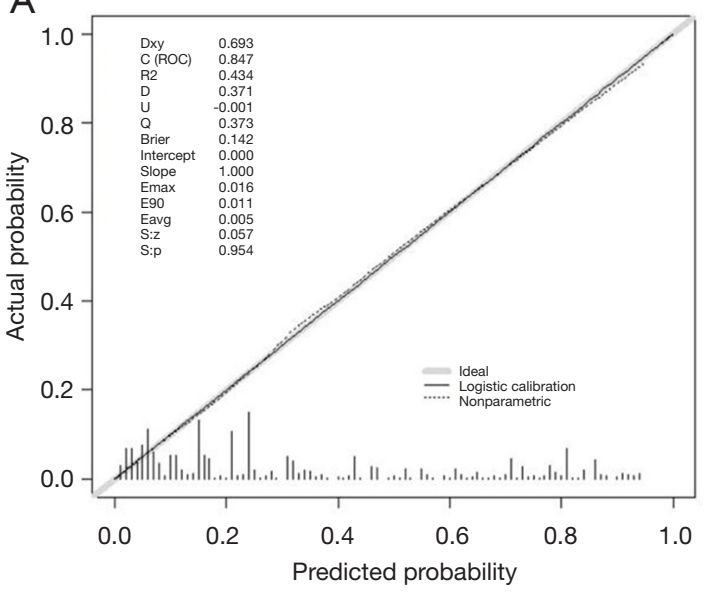

C

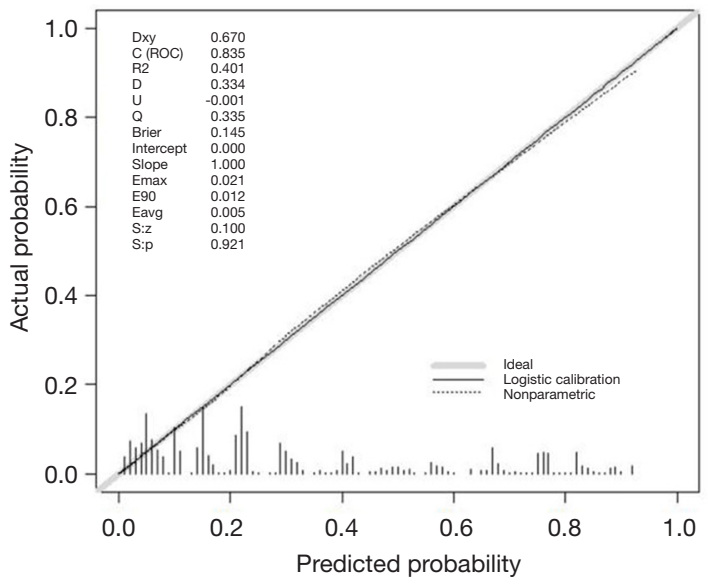

B

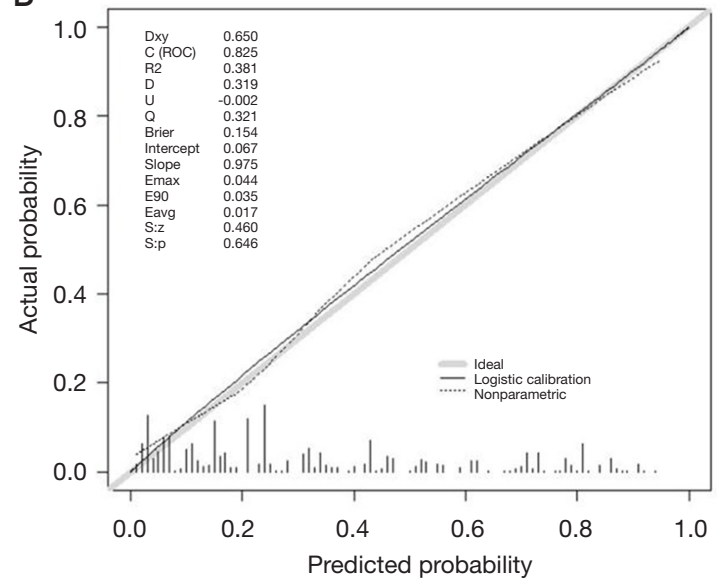

D

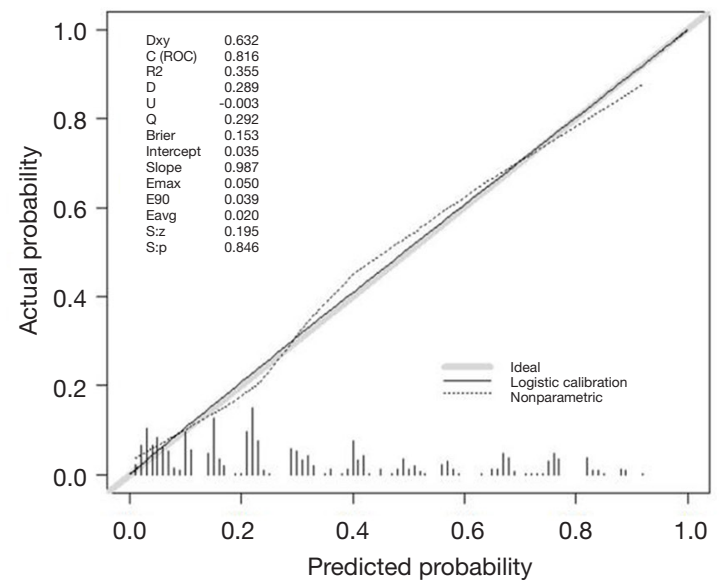

Figure 6 Calibration curves for assessing the calibration of the nomogram in predicting all-causes and cancer-specific early death in the training cohort (A, B) and the validation cohort (C, D).

schedule. To facilitate the use of these models, we developed the nomograms associated with web-based calculators.

Despite the advantages of our study, several potential limitations should also be considered. Firstly, detailed information on some factors that may influence the risk of early death, such as physical conditions and peritoneal metastasis, was not reported in the SEER database. Second, the present study was retrospective, and selection bias might exist. Third, we only included GC patients who were diagnosed with metastatic disease at initial diagnosis. We could not analyze the impact of metachronous metastasis on early death, which was not recorded in the SEER database. Therefore, more future studies may be needed to verify our results.

\section{Conclusions}

Approximately one-third of the stage IV GC patients died within three months. The early mortality remained stable during 2010-2015. A series of factors were found to be the independent risk factors associated with all-cause early death and cancer-specific early death in our study, including non-API race, poorer differentiation, middle sites of the stomach, lung metastases, liver metastases, no radiotherapy, no chemotherapy and no surgery. Two reliable nomograms were further developed to predict the risk of all-cause early death and cancer-specific early death. These risk factors and nomograms may be useful to assist clinicians in identifying the patients with the high risk of early death and provide 
A

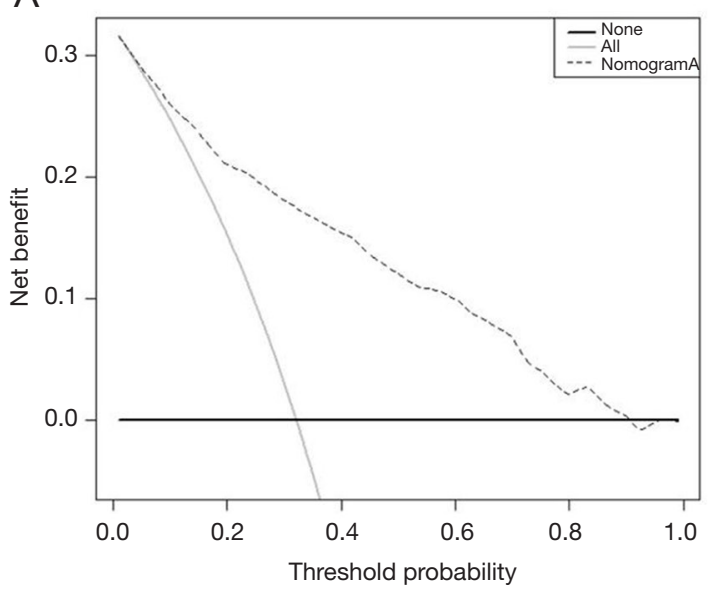

C

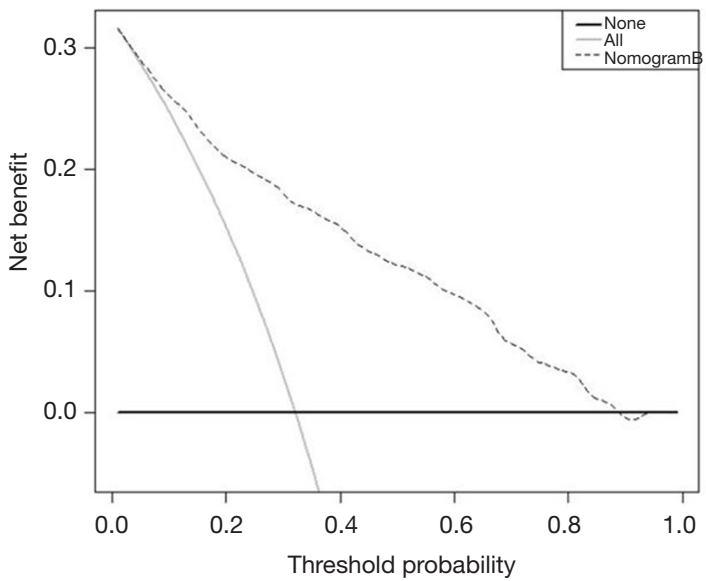

B

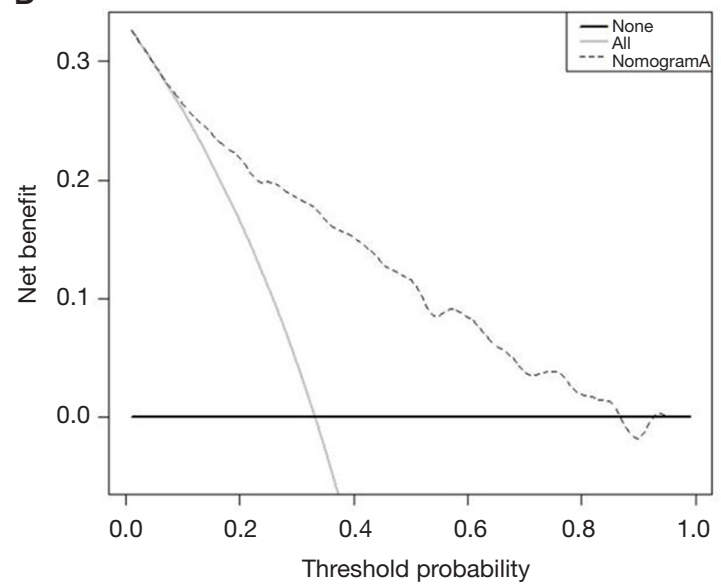

D

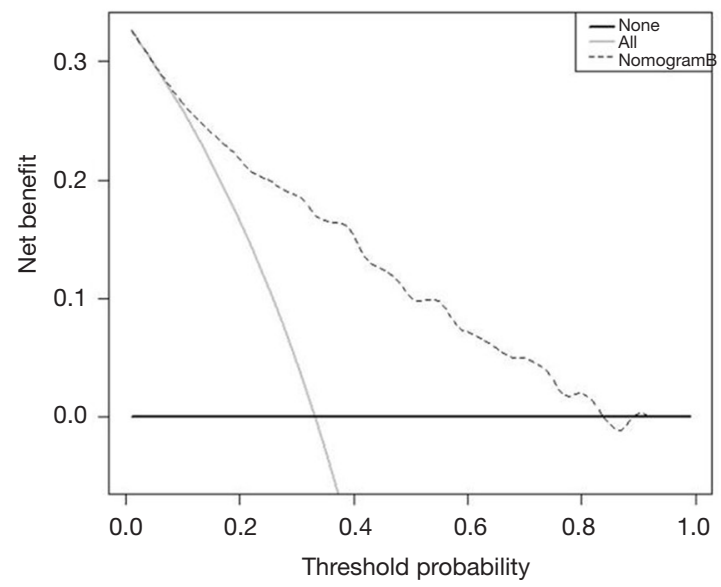

Figure 7 Decision curve analyses (DCAs) for the nomograms in predicting all-causes early death and cancer-specific early death in the training cohort (A, B) and the validation cohort $(\mathrm{C}, \mathrm{D})$.

insight into the clinical judgment and treatment plan options.

\section{Acknowledgments}

The authors thank AME Editing Service for English language editing.

Funding: This work was supported by the Science and Technology Foundation, Suzhou, Jiangsu (grant numbers SYS2019054).

\section{Footnote}

Reporting Checklist: The authors present the study in accordance with the TRIPOD reporting checklist. Available at http://dx.doi.org/10.21037/jgo-20-217

Conflicts of Interest: All authors have completed the ICMJE uniform disclosure form (available at http://dx.doi. org/10.21037/jgo-20-217). The authors have no conflicts of interest to declare.

Ethical Statement: The authors are accountable for all aspects of the work in ensuring that questions related to the accuracy or integrity of any part of the work are appropriately investigated and resolved. The SEER database is an open-access cancer database that only contains deidentified patient data. Therefore, this study was exempted from the approval by the institutional review board of the First Affiliated Hospital of Soochow University. The 
study was conducted in accordance with the Declaration of Helsinki (as revised in 2013).

Open Access Statement: This is an Open Access article distributed in accordance with the Creative Commons Attribution-NonCommercial-NoDerivs 4.0 International License (CC BY-NC-ND 4.0), which permits the noncommercial replication and distribution of the article with the strict proviso that no changes or edits are made and the original work is properly cited (including links to both the formal publication through the relevant DOI and the license). See: https://creativecommons.org/licenses/by-nc-nd/4.0/.

\section{References}

1. Bray F, Ferlay J, Soerjomataram I, et al. Global cancer statistics 2018: GLOBOCAN estimates of incidence and mortality worldwide for 36 cancers in 185 countries. CA Cancer J Clin 2018;68:394-424.

2. Jim MA, Pinheiro PS, Carreira H, et al. Stomach cancer survival in the United States by race and stage (2001-2009): Findings from the CONCORD-2 study. Cancer 2017;123 Suppl 24:4994-5013.

3. Chang YR, Han DS, Kong SH, et al. The value of palliative gastrectomy in gastric cancer with distant metastasis. Ann Surg Oncol 2012;19:1231-9.

4. Yamaguchi K, Yoshida K, Tanahashi T, et al. The longterm survival of stage IV gastric cancer patients with conversion therapy. Gastric Cancer 2018;21:315-23.

5. Zhao L, Li J, Bai C, et al. Multi-Modality Treatment for Patients With Metastatic Gastric Cancer: A Real-World Study in China. Front Oncol 2019;9:1155.

6. Ajani JA, Lee J, Sano T, et al. Gastric adenocarcinoma. Nat Rev Dis Primers 2017;3:17036.

7. Yoshida K, Yamaguchi K, Okumura N, et al. Is conversion therapy possible in stage IV gastric cancer: the proposal of new biological categories of classification. Gastric Cancer 2016;19:329-38.

8. Ebinger SM, Warschkow R, Tarantino I, et al. Modest overall survival improvements from 1998 to 2009 in metastatic gastric cancer patients: a population-based SEER analysis. Gastric Cancer 2016;19:723-34.

9. Abdel-Rahman O. A 10-year review of survival among patients with metastatic gastrointestinal cancers: a population-based study. Int J Colorectal Dis 2020;35:911-20.

10. Jochems A, El-Naqa I, Kessler M, et al. A prediction model for early death in non-small cell lung cancer patients following curative-intent chemoradiotherapy. Acta Oncol 2018;57:226-30.

11. Inoue T, Tamiya M, Tamiya A, et al. Analysis of Early Death in Japanese Patients With Advanced Non-small-cell Lung Cancer Treated With Nivolumab. Clin Lung Cancer 2018;19:e171-6.

12. Wang X, Mao M, Xu G, et al. The incidence, associated factors, and predictive nomogram for early death in stage IV colorectal cancer. Int J Colorectal Dis 2019;34:1189-201.

13. Lin JX, Desiderio J, Lin JP, et al. Multicenter Validation Study of the American Joint Commission on Cancer (8th Edition) for Gastric Cancer: Proposal for a Simplified and Improved TNM Staging System. J Cancer 2020;11:3483-91.

14. Brierley J, Gospodarowicz M, O'Sullivan B. The principles of cancer staging. Ecancermedicalscience 2016;10:ed61.

15. Son T, Sun J, Choi S, et al. Multi-institutional validation of the 8th AJCC TNM staging system for gastric cancer: Analysis of survival data from high-volume Eastern centers and the SEER database. J Surg Oncol 2019;120:676-84.

16. Ge XY, Ge F, Wang Z, et al. Analysis of risk factors of stage IV gastric cancer from the SEER database. Ann R Coll Surg Engl 2020;102:355-62.

17. Ma T, Wu ZJ, Xu H, et al. Nomograms for predicting survival in patients with metastatic gastric adenocarcinoma who undergo palliative gastrectomy. BMC Cancer 2019;19:852.

18. Min SH, Won Y, Lee K, et al. Laparoscopic gastrectomy and metastasectomy for stage IV gastric cancer. Surg Endosc 2020. [Epub ahead of print].

19. Liang C, Chen H, Yang Z, et al. Risk factors and prognosis of bone metastases in newly diagnosed gastric cancer. Future Oncol 2020;16:733-48.

20. Xie SH, Chen H, Lagergren J. Causes of death in patients diagnosed with gastric adenocarcinoma in 19702014 in Sweden: A population-based study. Cancer Sci 2020;111:2451-9.

21. Afifi AM, Saad AM, Al-Husseini MJ, et al. Causes of death after breast cancer diagnosis: A US population-based analysis. Cancer 2020;126:1559-67.

22. Sturgeon KM, Deng L, Bluethmann SM, et al. A population-based study of cardiovascular disease mortality risk in US cancer patients. Eur Heart J 2019;40:3889-97.

23. Kong J, Diao X, Diao F, et al. Causes of death in longterm bladder cancer survivors: A population-based study. Asia Pac J Clin Oncol 2019;15:e167-74.

24. Gad MM, Saad AM, Al-Husseini MJ, et al. Temporal trends, ethnic determinants, and short-term and long-term 
risk of cardiac death in cancer patients: a cohort study.

Cardiovasc Pathol 2019;43:107147.

25. Herrmann J. From trends to transformation: where cardio-oncology is to make a difference. Eur Heart J 2019;40:3898-900.

26. Zhang Y, Lin Y, Duan J, et al. A Population-Based Analysis of Distant Metastasis in Stage IV Gastric Cancer. Med Sci Monit 2020;26:e923867.

27. Taniguchi Y, Tamiya A, Nakahama K, et al. Impact of metastatic status on the prognosis of EGFR mutationpositive non-small cell lung cancer patients treated with first-generation EGFR-tyrosine kinase inhibitors. Oncol Lett 2017;14:7589-96.

28. Goldie JH, Coldman AJ. The genetic origin of drug resistance in neoplasms: implications for systemic therapy. Cancer Res 1984;44:3643-53.

29. Wu C, Wang N, Zhou H, et al. Development and validation of a nomogram to individually predict survival of young patients with nonmetastatic gastric cancer: A retrospective cohort study. Saudi J Gastroenterol 2019;25:236-44.

30. Rana N, Gosain R, Lemini R, et al. Socio-Demographic Disparities in Gastric Adenocarcinoma: A Population-

Based Study. Cancers (Basel) 2020;12:157.

31. Abdel-Rahman O. Asian Americans have better outcomes of non-metastatic gastric cancer compared to other United States racial groups: A secondary analysis from a randomized study. World J Gastrointest Oncol 2019;11:1151-60.

32. Jin H, Pinheiro PS, Callahan KE, et al. Examining the gastric cancer survival gap between Asians and whites in the United States. Gastric Cancer 2017;20:573-82.

33. Zhang G, Zhao X, Li J, et al. Racial disparities in stagespecific gastric cancer: analysis of results from the Surveillance Epidemiology and End Results (SEER) program database. J Investig Med 2017;65:991-8.

34. Ulanja MB, Beutler BD, Rishi M, et al. Influence of race and geographic setting on the management of gastric adenocarcinoma. J Surg Oncol 2019;120:270-9.

Cite this article as: Yang Y, Chen ZJ, Yan S. The incidence, risk factors and predictive nomograms for early death among patients with stage IV gastric cancer: a population-based study. J Gastrointest Oncol 2020;11(5):964-982. doi: 10.21037/jgo-20-217
35. Fujitani K, Yang HK, Mizusawa J, et al. Gastrectomy plus chemotherapy versus chemotherapy alone for advanced gastric cancer with a single non-curable factor (REGATTA): a phase 3, randomised controlled trial. Lancet Oncol 2016;17:309-18.

36. Kulig P, Sierzega M, Kowalczyk T, et al. Non-curative gastrectomy for metastatic gastric cancer: rationale and long-term outcome in multicenter settings. Eur J Surg Oncol 2012;38:490-6.

37. Yazıc1 O, Ozdemir N, Duran AO, et al. The effect of the gastrectomy on survival in patients with metastatic gastric cancer: a study of ASMO. Future Oncol 2016;12:343-54.

38. Hsu JT, Liao JA, Chuang HC, et al. Palliative gastrectomy is beneficial in selected cases of metastatic gastric cancer. BMC Palliat Care 2017;16:19.

39. Sun J, Song Y, Wang Z, et al. Clinical significance of palliative gastrectomy on the survival of patients with incurable advanced gastric cancer: a systematic review and meta-analysis. BMC Cancer 2013;13:577.

40. Narita Y, Kadowaki S, Oze I, et al. Establishment and validation of prognostic nomograms in first-line metastatic gastric cancer patients. J Gastrointest Oncol 2018;9:52-63.

41. Gao Z, Ni J, Ding H, et al. A nomogram for prediction of stage III/IV gastric cancer outcome after surgery: A multicenter population-based study. Cancer Med 2020;9:5490-9.

42. Wani S, Drahos J, Cook MB, et al. Comparison of endoscopic therapies and surgical resection in patients with early esophageal cancer: a population-based study. Gastrointest Endosc 2014;79:224-32.e1.

43. Wang J, Yang B, Li Z, et al. Nomogram-based prediction of survival in unresectable or metastatic gastric cancer patients with good performance status who received firstline chemotherapy. Ann Transl Med 2020;8:311.

44. Kim SY, Yoon MJ, Park YI, et al. Nomograms predicting survival of patients with unresectable or metastatic gastric cancer who receive combination cytotoxic chemotherapy as first-line treatment. Gastric Cancer 2018;21:453-63. 